\title{
Predicting floodplain inundation and vegetation dynamics in arid wetlands
}

\author{
Steven G. Sandi ${ }^{1, *}$,Patricia M. Saco ${ }^{1}$, George Kuczera ${ }^{1}, L i \mathrm{Wen}^{2}$, Neil Saintilan ${ }^{3}$, and Jose F. \\ Rodriguez ${ }^{1}$ \\ ${ }^{1}$ School of Engineering, University of Newcastle, Newcastle, NSW, Australia \\ ${ }^{2}$ Science Division, NSW Office of Environment and Heritage, Sydney, NSW, Australia \\ ${ }^{3}$ Department of Environmental Sciences, Macquarie University, North Ryde, NSW, Australia
}

\begin{abstract}
The Macquarie Marshes is a freshwater wetland system located in semiarid Australia. The ecological importance of this site has been recognized under the Ramsar convention. Plant associations in the marshes has shown a complex dynamic where some wetland vegetation patches have transitioned to terrestrial vegetation during severe drought, but also quickly responded to increased inflows due to record and near record rainfall accompanied by water releases from an upstream reservoir. Management decisions regarding the environmental flows require the use of predictive tools in order to assess the response of the vegetation. We have developed a vegetation response model that couples hydrodynamic modelling of the northern Macquarie Marshes with watering requirements of different plant associations and vegetation succession rules. The model simulates floods in the wetland during a series of years, after which patches of vegetation are analysed according to water depth, percent exceedance time and frequencies of inundation. During the simulated period, the patch can have adequate watering conditions, or it can have critical conditions that would lead to a succession to another type of vegetation. The predicted vegetation is reintroduced in the model, providing feedbacks for the next simulation period. In this contribution, we implemented the model to simulate changes of wetland understory during the period 1991 to 2014.
\end{abstract}

\section{Introduction}

Floodplains and wetlands of the Murray Darling basin (Fig. 1c), one of the most productive basins in Australia, have been affected by reduced flows due to dams, earthworks and other river management structures that disconnect floodplains from the main rivers [1-3]. These effects include the reduction of water volumes delivered to wetland systems, water quality, deterioration of vegetation conditions, and reductions of breeding populations of waterbirds and fisheries [4 and references therein]. However, the effects of water diversions on wetland systems of the Murray Darling Basin have not been completely quantified and some of the impacts are undoubtedly related to the changing climate [5]. This fact is of major concern because further wetland deterioration is expected to occur under current climate change projections [6]. This contribution focusses on the development of a dynamic vegetation

* Corresponding author: Steven.SandiRojas@newcastle.edu.au 
model in order to analyze the evolution of plant communities of the Macquarie Marshes, one of the most recognized environmental assets of the Murray Darling basin. Although recent investigations have greatly improved the understanding of the wetland ecosystem dynamics and addressed the necessity of predictive models to assist regulatory authorities on informed decision making [7], quantification and prediction of vegetation changes in the short and midterm under current water sharing plans and climate change projections are necessary.

Our approach predicts changes in a series of patches that have been recognized to shift in vegetation state during an extended drought period and subsequent recovery after a few years of inundation. A hydrodynamic model is implemented to calculate variables of the water regime which can predict shifts in the vegetation based on minimal water requirements for various plant associations. The model was implemented to simulate changes in the vegetation extent observed during the millennium drought period that affected Australia in the 2000's. Results show that our framework is capable of reproducing most of the changes observed in the understory vegetation of the Macquarie Marshes and it can be used to analyse future scenarios.

\subsection{Study site}

The research focuses on the study of the vegetation of the northern Macquarie Marshes (Fig. 1). The area was chosen because it includes most of the unique vegetation communities of the marshes and because it includes the Ramsar gazetted Macquarie Marshes Nature Reserve. The water balance of the Macquarie Marshes presents a typical deficit of semiarid climates where mean rainfall values range from 400 to $500 \mathrm{~mm}$ annually, while evapotranspiration can reach values between 1500 and $2000 \mathrm{~mm}$ per year [8]. Discharge entering the system is regulated by water releases from an upstream dam. Most of the discharge that reaches the northern Macquarie Marshes is recorded at a gauging station located at Pillicawarrina (station No.421147) (Fig. 1b) with a mean annual discharge of $6 \mathrm{~m}^{3} / \mathrm{s}$, and a mean annual runoff volume of $192 \times 10^{6} \mathrm{~m}^{3}$. Flows in the Macquarie River are not only irregular on a monthly scale (seasonal), but also on an interannual and interdecadal scales due to El Niño Southern Oscillation (ENSO) [8]. Additionally, in the reach from the Burrendong dam to the marshes, flows are diverted for agricultural and domestic purposes by a series of control structures such as weirs, regulators, bypass canals, earthen embankments, irrigation channels and siphons $[3,8]$ which contribute to the irregularity of the flows reaching the marshes. There is also a significant reduction in the discharge downstream within the Macquarie Marshes system; consequently, the northern Macquarie Marshes is the last asset within the wetland system to receive environmental flows [9].

The Macquarie Marshes are a constantly evolving wetland system that have lasted for thousands of years [10]. The site was an important settlement for the Wailwan people before European colonization, after which cattle stations and agriculture were established in the region since 1830's and large scale irrigated agriculture started after the construction of the Burrrengdon dam in 1967 [11 and references therein]. Concerns of the effects of human intervention on the site predate the construction of the dam. As early as 1900's, areas of the Macquarie Marshes have been protected to be used as a sanctuary for native fauna [12 and references therein].

Wetland systems located in dryland environments receive periodical floods that are key for ecological persistence [13]. After floods, wetlands show increases in productivity [14] because the flood delivers sediment and nutrients to the floodplain, it allows aquatic species to reach floodplain environments or distant waterholes, and it triggers different processes in the lifespan of some species such as waterbirds breeding cycles [13 and references therein]. After extended drought conditions in the 2000's, deterioration of the vegetation condition of the marshes was reported [15] which lead to many patches of wetland understory vegetation 
to undergo succession to terrestrial vegetation. Although many patches recovered after the breaking of the drought in 2009 due to environmental water delivery and record and near record rainfall, the resilience of the vegetation was directly affected by the reduced inundation frequency during the drought $[16,17]$. Further changes in vegetation are expected under current projections of climate change [18], but current studies have not been able to quantify these changes.

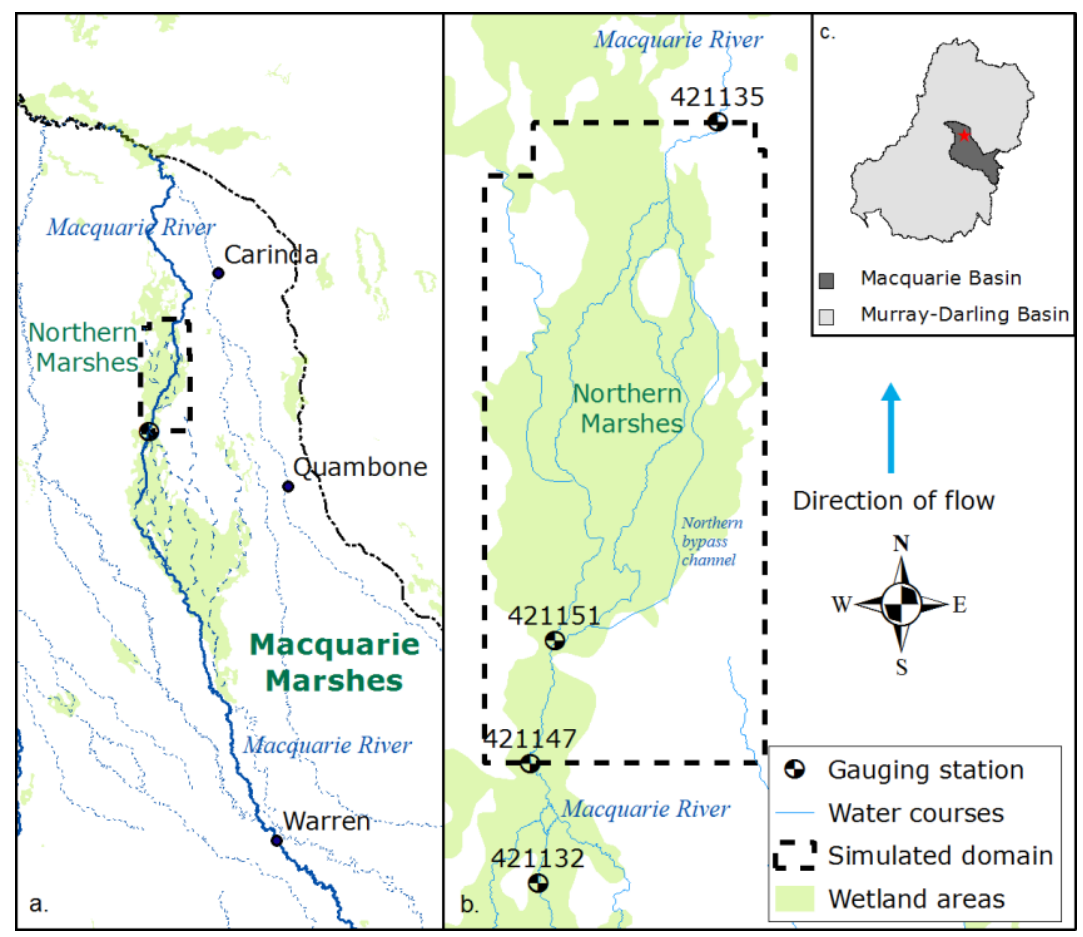

Fig. 1. a) Location of the northern Macquarie Marshes in the lower floodplain of the Macquarie River. b) Details of the simulated domain of the northern Macquarie Marshes. c) Location of the Macquarie Marshes in relation to the Macquarie River Basin and the Murray Darling Basin.

\section{Methods}

The framework uses a hydrodynamic model to calculate daily inundation patterns of the northern Macquarie Marshes by using discharge records from gauging station No.421147 (Fig 1b). The hydrodynamic model used is a quasi-two-dimensional model [19] built over a squared domain grid with a resolution of $90 \times 90 \mathrm{~m}$. Performance and calibration of the model was carried similarly to [20]. An important limitation of the model is that is does not have infiltration or evapotranspiration modules. Additionally, during high flows the water enters the domain along the floodplain so the discharge measured at station No.421147 is an underestimation of the total inflow. To some extent, this fact compensates for infiltration and evapotranspiration.

Simulations are carried out annually as the model is mainly intended to assist on the current management of the site. The short-term scale analysis allows the introduction of feedback from vegetation changes into the hydrodynamic model in small time steps, consistent with reported changes of understory vegetation in the site. Updates are introduced in the hydrodynamic model by updating the hydraulic resistance every five years according 
to vegetation changes. This consideration assumes some lag time between the predicted change of the vegetation and the direct effects on hydraulic flow. This assumption allows the model to reach a certain equilibrium before updating all hydrodynamic resistance parameters.

The vegetation model is set up on the same cell-grid domain of the two-dimensional hydrodynamic model and annual simulations are carried out using hydrologic years (June to May) instead of calendar years (January to December) because May and June represent months of low flows. Vegetation evolution of understory species is computed from an initial observed state of the vegetation represented as a number of patches with homogeneous cover of the vegetation. In this contribution we focus on four different understory species: Terrestrial vegetation, Water couch, Common reed, and Mixed marsh. Water requirements of these plant associations have been described in terms of four variables: frequency of inundation, timing, duration of the flood, and inundation depth [21, 22]. Depth and duration of inundation are combined as percent exceedance curves calculated annually for every cell of the grid.

The percentage area of the patch with adequate watering conditions is obtained from exceedance curves calculated at every cell in the patch. The frequency of inundation is assessed by considering thresholds of areas in the patch that present adequate inundation over time. The use of area thresholds as transition rules has already been discussed in previous publications [23-26] and they are the result of combining theoretical water requirements for different plant associations [21, 22], hydrodynamic simulation of the flooding patterns in the marshes and vegetation seasonal fractional cover maps [27]. Thresholds for vegetation succession have been established in terms of areas of the patch with adequate theoretical watering conditions and areas with minimum inundation for maintenance (three months), as suggested by the wetland site management [28]. A counter is used in each patch of vegetation to track the years in which the hydraulic regime was below the threshold, therefore not being adequate for the vegetation of the patch. If the counter reaches a critical frequency value, a succession of understory wetland vegetation to terrestrial vegetation occurs in the patch. On the other hand, wetland understory vegetation can colonize a patch of terrestrial vegetation after a sequence consecutive years with adequate water conditions above the threshold. In this contribution, the critical frequency for wetland vegetation succession was considered to be three years below or above the threshold, based on the available observed data. Previous vegetation cover of the patch is given priority if recolonization is being considered.

The analysis of different vegetation patches showed consistent results with persistence probability estimated for River red gum and understory species [7]. Changes in the extent of the vegetation are calculated for a series of 23 years of consecutive flows (1991-2013). The model was tested by comparing simulated vegetation extent with vegetation maps of the Macquarie Marshes obtained by the NSW Office of Environment and Heritage for the years 2008 and 2013. Changes in the spatial distribution of overstory vegetation patches of River red gum association and Floodplain vegetation were small in the period of analysis (19912008) and are not included in the analysis carried on this publication.

\section{Results and discussion}

Available vegetation maps derived from aerial photography for the years 1991, 2008 [15] and 2013 were resampled to the resolution of the simulated domain (90x90 m grid) and a total of 119 vegetation patches were selected for the final setup of the vegetation model (Fig. 2). Vegetation patches located west of the Northern bypass channel (Fig. 1b) were not included because of their relative isolation and complex hydrodynamics, which contributed to underestimation of simulated floods in this particular areas of the domain. Fig. 3 shows the variation of simulated extent for four vegetation associations: Terrestrial vegetation, Common reed, Mixed marsh and Water couch. Floodplain vegetation and River red gum 
associations shown in Fig. 2 were considered unchanged during this period, as only $1 \%$ area of these associations transitioned to other species. The condition of overstory species is not assessed in this contribution.
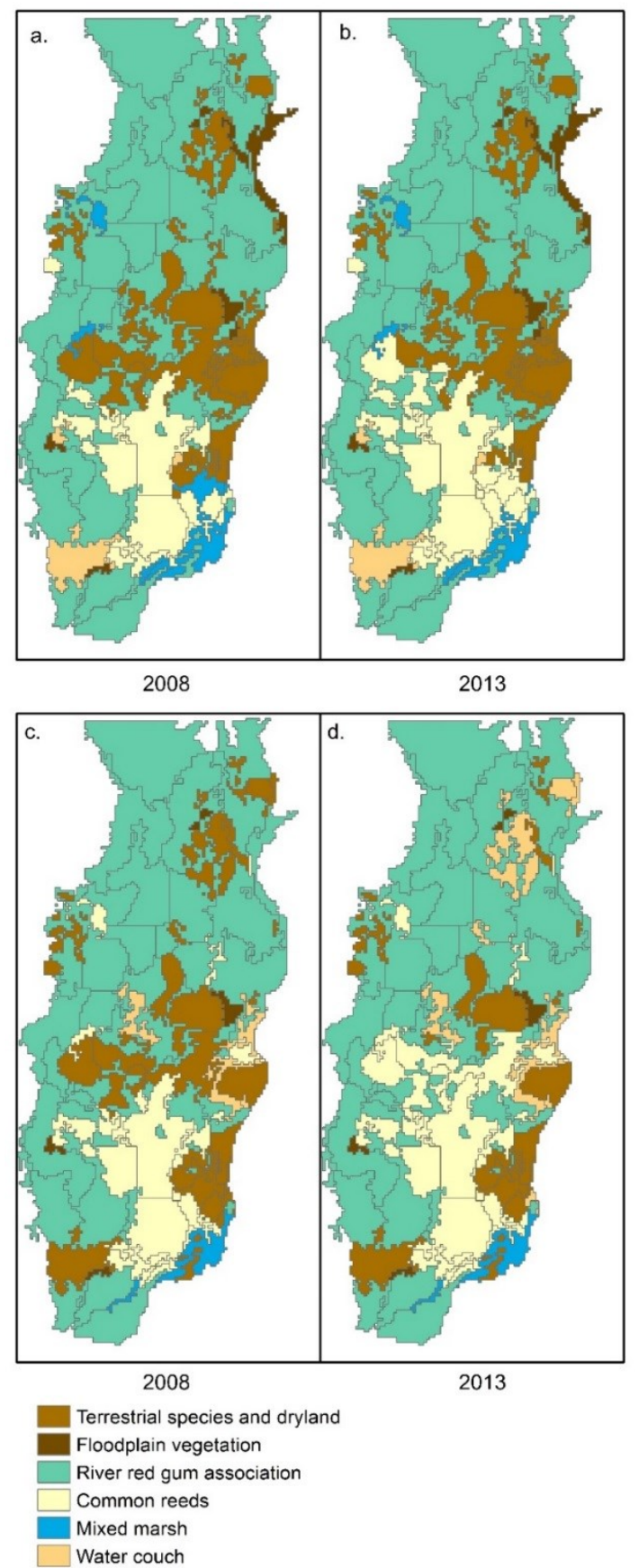

Fig. 2. a,b) Observed vegetation in 2008 and 2013 respectively. c,d) Simulated vegetation in 2008 and 2013 respectively. 
An important consideration in regards to the simulation of understory wetland vegetation is that they correspond to hydrologic years, which start on June (beginning of winter) and end in May (end of autumn) of the next year. This is because May and June often have low flows, thus allowing for faster spin-up of the hydrodynamic model. More importantly, the theoretical requirement for inundation timing in all the vegetation associations is from spring to summer (September to February) [21]. By considering hydrologic years, the model implicitly captures the influence of inundation timing and the obtained vegetation distributions are an estimate of the vegetation at the end of the hydrologic year.

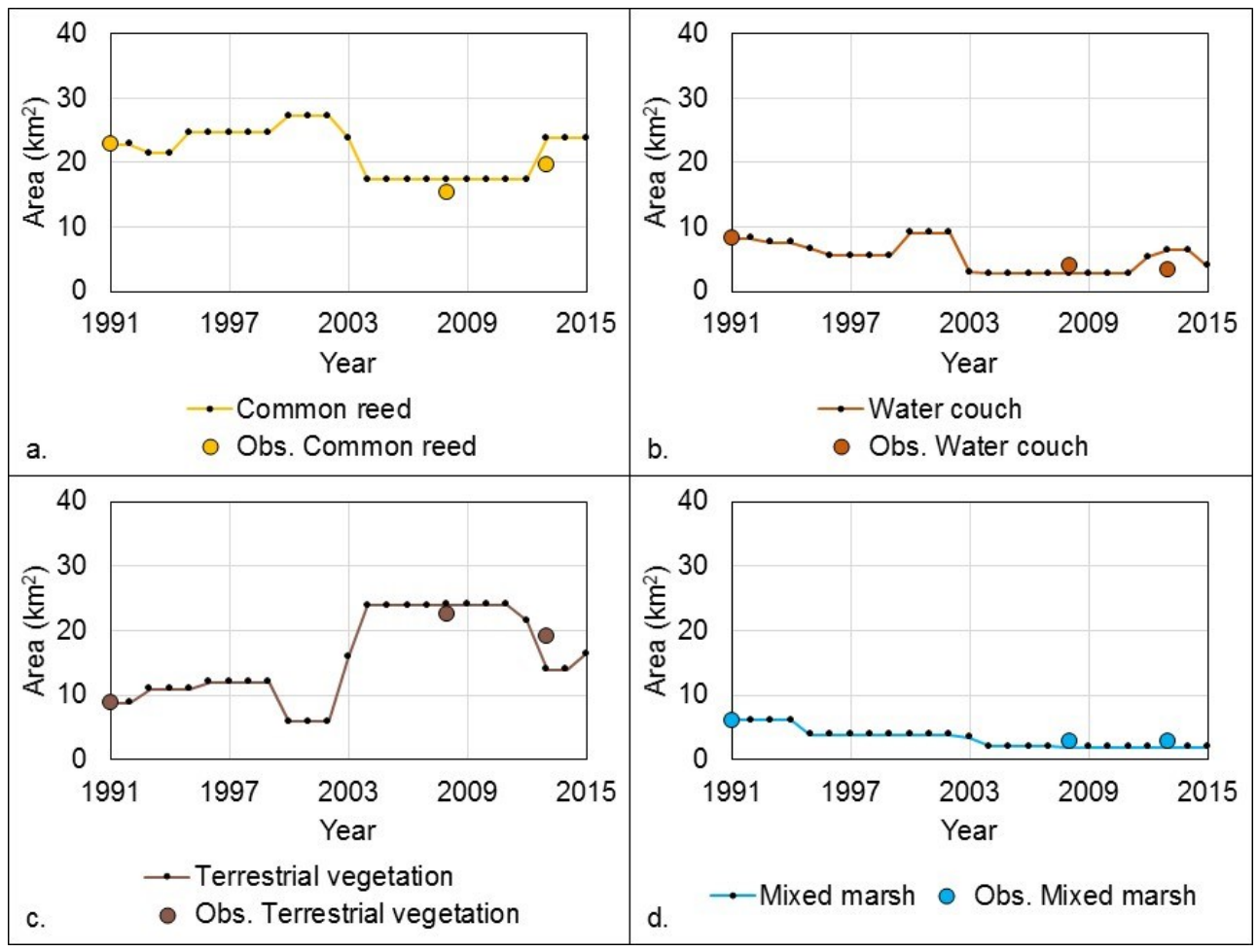

Fig. 3. Simulated extent of four different vegetation associations in the Macquarie Marshes and observed extents in the years 2008 and 2013: a) Common reed, b) Water couch, c) Terrestrial vegetation and d) Mixed marsh.

Figs. 2 and 3 show spatially distributed and integrated comparisons between modelled and observed wetland vegetation distributions. For 2008, the model predicts a good approximation of the spatial extent of the four vegetation associations when compared to observed vegetation (Fig. 2a,c). Fig. 3, shows how wetland understory deterioration started in the northern Macquarie Marshes by early 1990's, but the worst conditions for the vegetation were reached during the peak of the drought (2001-2009). Simulation of Common reed and Mixed marsh extension for 2008 are consistent with the extension reported for that same year (Fig. 2a,c). For Water couch, even though the total extent was correctly simulated (Fig. 3b), the simulated distribution show some inconsistencies. The simulation incorrectly predicts a loss of the large Water couch patch located in the southern part of the domain (Fig. 2a,c), while it also fails to predict the survival of small patches in the mid-section. In 2013 the model predicts a higher recovery of Common reed and Water couch patches than the observed distribution (Fig 2b,d), with some Water couch colonizing patches located in the northern areas of the domain and significant recoveries of Common reed in the midsection. Overall, the model was able to represent the deterioration of the vegetation during the drought 
period of the 2000's, but overestimates later recovery of some of the patches in 2013 (Fig. 3 ). In any case, the predictions in term of vegetation extent are remarkably accurate (Fig. 3) and further improvement in the results can be achieved with adjustment of the critical frequencies threshold.

\section{Conclusion}

In this contribution, a modelling framework was developed for the analysis of vegetation changes in the northern Macquarie Marshes. The model was used to simulate the vegetation dynamics in the northern Marshes during the millennium drought in the 2000's. The model was able to quantify vegetation changes and vegetation extent of this freshwater wetland with many different vegetation associations. The methods developed in this contribution can be extrapolated to other freshwater wetlands in the Murray-Darling Basin to quantify changes or vegetation conditions under future water sharing scenarios. The framework, however, has important limitations for determining future climate change impacts as these type of analyses often require an integrated assessment at different scales. This can be achieved with a basin scale hydrological model that downscales climate change information and recreates flows reaching the wetlands. Our model can then be applied to quantify vegetation changes.

\section{References}

1. Kingsford, R.T., Ecological impacts of dams, water diversions and river management on floodplain wetlands in Australia. Austral Ecology, 2000. 25(2): p. 109-127.

2. Steinfeld, C.M. and R.T. Kingsford, Floodplain development \& vegetation health on the Macquarie River floodplain of the Murray-Darling Basin. 2008: University of New South Wales.

3. Steinfeld, C.M.M. and R.T. Kingsford, Disconnecting the Floodplain: Earthworks and Their Ecological Effect on a Dryland Floodplain in the Murray-Darling Basin, Australia. River Research and Applications, 2013. 29(2): p. 206-218.

4. Pittock, J. and C.M. Finlayson, Australia's Murray-Darling Basin: freshwater ecosystem conservation options in an era of climate change. Marine and Freshwater Research, 2011. 62(3): p. 232-243.

5. Finlayson, C.M., et al., The status of wetlands and the predicted effects of global climate change: the situation in Australia. Aquatic Sciences, 2013. 75(1): p. 73-93.

6. CSIRO, Water availability in the Murray-Darling Basin. A report to the Australian Government from the CSIRO in Murray-Darling Basin Sustainable Yields Project. 2008, CSIRO: Australia. p. 67.

7. Bino, G., et al., Developing state and transition models of floodplain vegetation dynamics as a tool for conservation decision-making: a case study of the Macquarie Marshes Ramsar wetland. Journal of Applied Ecology, 2015. 52(3): p. 654-664.

8. Ralph, T.J. and P.P. Hesse, Downstream hydrogeomorphic changes along the Macquarie River, southeastern Australia, leading to channel breakdown and floodplain wetlands. Geomorphology, 2010. 118(1-2): p. 48-64.

9. Driver, P. and C. Knight, Macquarie Marshes 2005/06 Environmental Flow. Responses of groundcover plants to environmental flow. Report to the Macquarie Marshes Environmental Flow Reference Group. 2007.

10. Yonge, D. and P.P. Hesse, Geomorphic environments, drainage breakdown, and channel and floodplain evolution on the lower Macquarie River, central-western New South Wales. Australian Journal of Earth Sciences, 2009. 56(sup1): p. 35-53. 
11. DECCW, Macquarie Marshes Adaptive Environmental Management Plan: Synthesis of information projects and actions. 2010, NSW Department of Environment, Climate Change and Water: Sydney.

12. Berney, P. and T. Hosking, Opportunities and challenges for water-dependent protected area management arising from water management reform in the MurrayDarling Basin: a case study from the Macquarie Marshes in Australia. Aquatic Conservation: Marine and Freshwater Ecosystems, 2016. 26: p. 12-28.

13. Leigh, C., et al., Sequential floods drive booms and wetland persistence in dryland rivers: a synthesis. Marine and Freshwater Research, 2010. 61(8): p. 896-908.

14. Junk, W.J., P.B. Bayley, and R.E. Sparks, The flood pulse concept in riverfloodplain systems. Canadian special publication of fisheries and aquatic sciences, 1989. 106(1): p. 110-127.

15. Bowen, S. and S. Simpson, Changes in extent and condition of the vegetation communities of the Macquarie Marshes Floodplain 1991-2008: Final report to the NSW Wetland Recovery Program. 2010, River and Wetlands Unit, Department of Environment, Climate Change and Water, NSW: Sydney.

16. Rogers, K., T. Ralph, and S. Imgraben, Water requirements of biota, geomorphology and climate change in the Macquarie Marshes, in Ecosystem Response Modelling in the Murray-Darling Basin. CSIRO Publishing, Melbourne, N. Saintilan and I. Overton, Editors. 2010. p. 151-170.

17. Thomas, R., et al., Inundation response of vegetation communities of the Macquarie Marshes in semi-arid Australia, in Ecosystem response modelling in the MurrayDarling Basin. 2010, CSIRO Publishing: Melbourne. p. 137-150.

18. CSIRO, Water availability in the Macquarie-Castlereagh. A report to the Australian Government from the CSIRO, in Murray-Darling Basin Sustainable Yields Project. 2008, CSIRO: Australia. p. 144.

19. Riccardi, G., A cell model for hydrological-hydraulic modeling. Journal of Environmental Hydrology, 2000. 8.

20. Sandi-Rojas, S.G., et al., Macquarie river floodplain flow modeling: Implications for ecogeomorphology, in River Flow 2014, A.J. Schleiss, et al., Editors. 2014, CRC Press. p. 2347-2355.

21. Rogers, K., Vegetation, in Flodplain wetland biota in the Murray-Darling basin: Water and Habitat Requirements, K.R. Rogers, T., Editor. 2011: Australia. p. 1782.

22. Roberts, J. and F. Marston, Water regime for wetland and floodplain plants: $a$ source book for the Murray-Darling Basin. 2011, Canberra: National Water Commission.

23. Sandi, S.G., et al. Development of a Vegetation Dynamics Model for Freshwater Wetland Assesment in the Macquarie Marshes. in 36th Hydrology and Water Resources Symposium 2015. Hobart, Tasmania.

24. Sandi, S.G., et al., Linking Hydraulic Regime Characteristics to Vegetation Status in the Macquarie Marshes, in 11th International Symposium on Ecohydraulics. 2016: Melbourne, Australia.

25. Sandi, S.G., et al., Simulation of the vegetation state and flow regime interaction in the Macquarie Marshes, in River Flow 2016. 2016, CRC Press. p. 2013-2019.

26. Sandi, S.G., et al., Determining Critical Vegetation Conditions in the Macquarie Marshes Using an Eco-hydraulic Approach in 37th IAHR World Congress 2017 : Kuala Lumpur, Malaysia.

27. OEH, Seasonal fractional cover - Landsat, JRSRP algorithm, NSW coverage, Joint Remote Sensing Research Project. 2014.

28. Hosking, T., Peer communication (10 of October 2015). 2015. 